\title{
Efeito de Óleos Essenciais Sobre Bactérias Gram-Negativas Isoladas de Alimentos
}

\author{
Effect of Essential Oils on Food-Isolated Gram-Negative Bacteria Isolated
}

\author{
Bruno Antunes Contruccia ${ }^{\mathrm{a}}$ Rosimeire Silva ${ }^{\mathrm{b}}$; Roberto Andreani Junior ${ }^{\mathrm{b}}$; Dora Inés Kozusny-Andreani*a \\ ${ }^{a}$ Universidade Brasil. SP, Brasil. \\ bUniversidade Brasil, Programa de Pós-Graduação Stricto Sensu em Ciências Ambientais. SP, Brasil. \\ *E-mail: doraines@terra.com.br
}

\begin{abstract}
Resumo
Os óleos essenciais são produtos do metabolismo secundário de plantas e são conhecidos por possuir diferentes propriedades biológicas, incluindo atividades antimicrobianas, podendo agir como antibacteriano, antifúngico e antiviral. Objetivou-se nesta pesquisa avaliar a atividade antibacteriana de óleos essenciais sobre cepas de Escherichia coli e Pseudomonas aeruginosa isoladas de alimentos. Foram utilizados os óleos de Eucalyptus globolus (eucalipto comum), Prunus amygdalus (amêndoa), Cymbopongon nardus (citronela), Rosmarinus officinalis (alecrim), Cinnamomum zeylanicum (caneleira), Cymbopogon citratus (capim limão), Citrus limon (limão), Caryophyllus aromaticus (cravo). Foram utilizadas dez linhagens de E. coli e dez de P. aeuriginosa. Para determinação da Concentração Inibitória Mínima (CIM) dos óleos essenciais foi utilizado o método de microdiluição em placas de 96 poços. As concentrações bactericidas mínimas (CBM) foram determinadas a partir dos resultados da CIM. Designou-se como CBM a concentração mínima em que não ocorreu crescimento bacteriano. Verificou-se que todos os óleos essenciais apresentaram atividade antibacteriana, no entanto os óleos de E. gobulus e $R$. officinalis foram mais ativos frente a $E$. coli $(\mathrm{CBM}=3,13 \%)$, e menos eficazes frente a $P$. aeruginosa $(\mathrm{CBM}=25 \%)$, enquanto que o de $C$. nardus apresentou atividade biológica frente a $P$. aeruginosa na concentração de $6,25 \%$. A atividade antimicrobiana dos óleos essenciais testados aponta a possibilidade de desenvolver agentes antimicrobianos eficientes e de baixo custo no controle de E. coli e P. aeruginosa.
\end{abstract}

Palavras-chave: Escherichia coli. Pseudomonas aeruginosa. Plantas Medicinais. Controle.

\begin{abstract}
Essential oils are secondary plant metabolism produtcts and are known to have different biological properties, including antimicrobial activities, which may act as antibacterial, antifungal and antiviral. The objective of this research was to evaluate the essential oils antibacterial activity on strains of Escherichia coli and Pseudomonas aeruginosa isolated from food. Essential oils Eucalyptus globolus, Prunus amygdalus, Cymbopongon nardus, Rosmarinus officinalis, Cinnamomum zeylanicum, Cymbopogon citratus, Citrus limon, Caryophyllus aromaticus were used. Ten strains of E. coli and ten of P. aeuriginosa were used. To determine the Minimum Inhibitory Concentration (MIC) of the essential oils, the 96-well plate microdilution method was used. Minimum bactericidal concentrations (MBC) were determined from MIC results. CBM was the minimum concentration at which no bacterial growth occurred. It was verified that all the essential oils presented antibacterial activity, however the oils of Eucaliptus gobulus and Rosmarinus officinalis were more active against E. coli $(M B C=3.13 \%)$, and less effective against P. aeruginosa $(C B M=25 \%)$, while that of Cymbopongon nardus showed biological activity against P. aeruginosa at $6.25 \%$ concentration. The antimicrobial activity of the tested essential oils indicates the possibility of developing efficient and low cost antimicrobial agents in the control of E. coli and P. aeruginosa.
\end{abstract}

Keywords: Escherichia coli. Pseudomonas aeruginosa. Medicinal Plants. Control.

\section{Introdução}

A bactéria Escherichia coli constitui um grupo de Enterobactérias que, normalmente, habitam a microbiota intestinal do homem e de animais, sendo em sua grande maioria não patogênicas (FRACAROLLI; OLIVEIRA; MARZIALE, 2017). Pseudomonas aeruginosa é uma bactéria amplamente distribuída na natureza, podendo fazer parte da microbiota normal de indivíduos hígidos, sendo um patógeno importante pela resistência intrínseca a inúmeros antimicrobianos (TORTORA; FUNKE, CASE, 2012).

$\mathrm{O}$ uso indiscriminado de antibióticos resultou no surgimento de bactérias resistentes, sendo um grave problema que afeta a saúde pública (LOUREIRO et al, 2016, COSTA; SILVA JUNIOR, 2017; FRACAROLLI; OLIVEIRA;
MARZIALE, 2017). P. aeruginosa, Staphylococcus aureus, Salmonella spp, Staphylococcus coagulase-negativo, Shigella, Enterococcus sp. e E. coli são consideradas as principais bactérias com resistência múltipla a antimicrobianos e estão incluídas na categoria de patógenos comunitários e hospitalares. O tratamento das infecções causadas por estes micro-organismos é um grande desafio para o campo médico e, exigiu a busca de novas substâncias antimicrobianas de outras fontes, incluindo plantas (FISHER; PHILLIPS, 2008, CHOUHAN; SHARMA; GULERIA, 2017). Os extratos e os óleos essenciais obtidos a partir de muitas plantas aromáticas e medicinais apresentam atividades biológicas importantes no controle de patógenos (BOUKHRAZ et al., 2016). Os efeitos antimicrobianos de óleos essenciais são amplos, podendo agir como antibacteriano, antifúngico, antiparasitário, 
antioxidante, antiviral, anticancerígeno entre outros (SILVA; FERNANDES, 2010).

Óleos essenciais são produtos do metabolismo secundário de plantas e são conhecidos por possuir propriedades biológicas diferentes, incluindo atividades antimicrobianas São concentrados, extratos naturais, que foram provados ser boas fontes de compostos bioativos com propriedades antioxidantes e antimicrobianas (MAN et al., 2019). Por se tratar de produtos multicomponentes, podem exercer maior atividade antimicrobiana, quando comparados com componentes idividuais (LANGEVELD; VELDHUIZEN; BURT, 2014; MO; ADEBAYO, 2017). De acordo com Farisa et al. (2017), em função da natureza multicomponente dos óleos essenciais a resistência bacteriana é menos provável de ser desenvolvida, uma vez que esses óleos afetam numerosos alvos no patógeno. Os óleos essenciais exercem seu efeito antimicrobiano afetando, principalmente, a permeabilidade da membrana em unção da sua natureza lipofílica (SOLIMAN et al., 2017).

Contudo, a informação sobre bioatividade e toxicidade dos óleos essenciais não são extensivamente estudadas. Apesar disso, o uso comercial e as aplicações de óleos essenciais continuam a crescer, e são usados em produtos de limpeza domésticos, cosméticos, perfumaria, inseticidas, desinfetantes, na gestão de infecções em animais e humanas (ADUKWU et al., 2016). Neste contexto, objetivou-se avaliar a atividade antibacteriana de óleos essenciais sobre cepas de E. coli e $P$. aeruginosa isoladas de alimentos.

\section{Material e Métodos}

\section{1 Óleos essenciais}

Foram empregados óleos essenciais de eucalipto (Eucalyptus globolus L.), amêndoa (Prunus amygdalus L. var. dulcis.), citronela (Cymbopongon nardus (L) Rendle), alecrim (Rosmarinus officinalis L.), canela (Cinnamomum zeylanicum Blume), capim limão (Cymbopogon citratus (DC) Stapf.), limão (Citrus limon L. Burm. f.), cravo da Índia (Caryophyllus aromaticus L.), adquiridos no comércio de produtos naturais.

\subsection{Concentração inibitória mínima}

As concentrações inibitórias mínimas (CIM) foram determinadas em placas de microdiluição de 96 poços, de acordo com a metodologia preconizada pelo Clinical and Laboratory Standards Institute (CLSI, 2013). As concentrações dos óleos essenciais foram: 100\%, 50\%, 25\%, $12,5 \%, 6,25 \%, 3,13 \%, 1,57 \%, 0,78 \%, 0,39 \%, 0,20 \%, 0,10 \%$, $0,05 \%$ e $0,025 \%$ (v/v).

Para avaliação da atividade antibacteriana dos óleos essenciais foram utilizadas dez cepas de E. coli e dez cepas de $P$. aeruginosa, isoladas de alimentos. Quarenta e oito horas antes da realização do estudo, as cepas bacterianas foram revitalizadas em ágar sangue (Oxoid $\AA$ ), incubadas a $37{ }^{\circ} \mathrm{C}$, quando foi verificada a pureza das colônias. De cada cultura foi retirada uma colônias e transferida para $20 \mathrm{~mL}$ de caldo Triptecaseina Soja (TSB, Oxoid®), incubadas a a $37{ }^{\circ} \mathrm{C}$ por 24 horas, sob agitação orbital (250 rpm).

Após incubação foi preparado, em solução salina estéril, um inóculo padrão de 0,5 unidades de McFarland, que corresponde a $10^{8}$ unidades formadoras de colónias $\mathrm{L}^{-1}$ (10 $\left.\mathrm{UFC} \mathrm{L}^{-1}\right)$. Do inóculo padrão foram retirados quinze microlitros e transferidos em 985 microlitros de TSB estéril, obtendo-se um inóculo bacteriano de aproximadamente $10^{6}$ UFC.

Nas placas de microdiluição foram determinados os poços de controle negativo contendo 200 microlitros do meio TSB estéril e positivo contendo 100 microlitros do inóculo bacteriano sem óleos essenciais mais de 100 microlitros de TSB. Nos poços restantes foram transferidos 100 microlitros do inóculo e 100 microlitros de cada diluição dos óleos essenciais

As placas de microdiluição foram incubadas a $35{ }^{\circ} \mathrm{C}$ durante 18 horas em atmosfera normal, quando a CIM foi determinada pela adição, em cada poço, de 50 microlitros do corante 2,3,5-Triphenyltetrazolium Chloride (Sigma $\left.{ }^{\circledR}\right)$. Isto tornou possível distinguir as amostras vivas, coloridas de vermelho, daquelas mortas que mantiveram a sua cor. A CIM foi interpretada no último poço de cada fileira, em que não foi observado crescimento bacteriano visível, inibição do crescimento bacteriano (SYLVESTER, 2011).

\subsection{Concentração bactericida mínima}

As concentrações bactericidas mínimas (CBM) foram determinadas a partir dos três últimos poços, cada linha que não apresentou crescimento bacteriano após a incubação das placas. Para isso, 50 microlitros do poço correspondente foram inoculados em placas de ágar sangue. As placas foram incubadas por 24 horas a $37^{\circ} \mathrm{C}$. Designou-se como CBM a concentração mínima em que não ocorreu crescimento bacteriano (FAVRE et al., 2003).

\section{Resultados e Discussão}

No Quadro 1 estão apresentados os resultados da atividade antibacteriana dos óleos essenciais frente a $E$. coli. Foi constatada a atividade bactericida dos diferentes óleos essenciais em concentrações baixas, que variaram entre $1,57 \%$ e $25 \%$, exceto o óleo de Prunus amygdalus (amêndoa) que apresentou uma CIM e CBM de 50\%. Verificou-se bioatividade de todos os óleos essenciais avaliados em concentrações superiores a CIM e CBM, e ineficácia em concentrações inferiores a estas. 
Quadro 1 - Concentração inibitória mínima (CIM) e concentração bactericida mínima (CBM) de óleos essenciais, sobre Escherichia coli

\begin{tabular}{|l|c|c|}
\hline \multicolumn{1}{|c|}{ Tratamentos } & \multicolumn{2}{c|}{$\begin{array}{c}\text { Concentração de Óleos } \\
\text { Essenciais (\%) }\end{array}$} \\
\hline \multicolumn{1}{|c|}{ Nome científico } & CIM & CBM \\
\hline Cymbopongon nardus & 3,13 & 3,13 \\
\hline Eucaliptus globolus & 1,57 & 3,13 \\
\hline Prunus amygdalus & 50,00 & 50,00 \\
\hline Rosmarinus officinalis & 1,57 & 3,13 \\
\hline Cinnamomum zeylanicum & 3,13 & 3,13 \\
\hline Cymbopogon citratus & 12,50 & 12,50 \\
\hline Citrus limon & 25,00 & 25,00 \\
\hline Caryophyllus aromaticus & 12,50 & 12,50 \\
\hline
\end{tabular}

Fonte: Dados da pesquisa

Os óleos essenciais são produtos do metabolismo secundario das plantas e apresentam composição química de elevada complexidade. In vivo possuem a função de proteger os órgãos vegetais contra os micro-organismos fitopagênicos, conferindo-lhes características antimicrobianas. Os óleos essenciais de Eucaliptus globolus, Rosmarinus officinalis, Cymbopongon nardus, e Cinnamomum zeylanicum foram os mais ativos (Quadro 1), conseguiram atingir efeito bactericida em concentrações baixas $(1,57 \%-3,13 \%)$. Provavelmente, a atividade antibacteriana destes óleos está relacionada com as substâncias bioativas que os compõem. O óleo de E. globolus é constituído por cineol ou eucaliptol, $\alpha$-pineno, p-cimeno, limoneno, felandreno (TOMAZ et al., 2014), o de R.officinalis apresenta $\alpha$-pinemo, cânfora e o eucaliptol (CAMELO et al., 2014), enquanto que constituintes majoritários do óleo essencial de $C$. nardus são citronelal, geraniol e citronelol, e do óleo essencial de C. zeylanicum são: (E)- cinamaldeído, acetato de (E)-cinamila e 1,8-cineol (ANDRADE et al., 2012)

Resultados obtidos por Furtado et al. (2015) se contrapõem com os da presente pesquisa, apresentados no Quadro 1. Estes autores avaliaram a atividade antibacteriana de Eucalyptus globulus e Cymbopogon citratus com a bactéria E. coli, e verificaram ineficácia em todas as concentrações avaliadas (100\%, 50\% e 25\%). Guimarães et al. (2017) avaliariam a atividade antimicrobiana in vitro do extrato aquoso e do óleo essencial das espécies Rosmarinus officinalis L. (alecrim) e Caryophyllus aromaticus L. (cravo da índia) frente a linhagens padrão de Staphylococcus aureus e E. coli. Pelos resultados obtidos, os autores concluíram que o óleo essencial de cravo da índia apresentou atividade antimicrobiana para ambas as estirpes analisadas, enquanto que o óleo essencial de alecrim inibiu o crescimento da linhagem de E. coli

Os óleos essenciais das plantas Eucalyptus gobulus e Rosmarinus officinalis foram utilizados, por Djelloul, Mokrani e Hacini (2017), para evidenciar a atividade antibacteriana frente a três linhagens patogênicas, $S$. aureus, $P$. aeruginosa e E. coli. Os resultados obtidos mostraram atividade antibacteriana dos óleos essenciais em todas as cepas testadas. $E$. coli e $P$. aeruginosa foram os mais sensíveis, enquanto $S$. aureus foi o mais resistente. Na presente pesquisa se verificou que E. gobulus e $R$. officinalis foram mais ativos frente a E.coli $(\mathrm{CBM}=3,13 \%$, Quadro 1), e menos eficazes frente a P. aeruginosa (CBM=25\%, Quadro 2). Segundo Lima et al. (2019), nas bactérias gram-negativas, o óleo essencial de $E$. globulus apresentou ação antibacteriana frente aos diversos fenótipos de resistência envolvidos em falhas terapêuticas no ambiente hospitalar, com exceção para $P$. aeruginosa.

De acordo com Man et al. (2019), os cocos grampositivos são mais susceptíveis, seguidos pelos representantes da família Enterobacteriaceae (E. coli), enquanto frente a $P$. aeruginosa os óleos essenciais apresentam pouca atividade antibacteriana. Os resultados apresentados na Tabela 2 indicaram atividade antimicrobiana sobre $P$. aeruginosa da maioria dos óleos essenciais avaliados, no entato foi constatada baixa suscetibilidade de $P$. aeruginosa frente ao óleo de Caryophyllus aromaticus. Resultados obtidos por Batista et al. (2014) evidenciaram que os óleos essenciais de. Caryophyllus aromaticus apresentaram maior efeito inibitório sobre P. aeruginosa, com valor de CIM de 0,25\% $(\mathrm{v} / \mathrm{v})$, sendo discordantes com os obtidos na presente pesquisa, com valores de CIM de 100\% (Quadro 2).

Quadro 2 - Concentração inibitória mínima (CIM) e concentração bactericida mínima $(\mathrm{CBM})$ de óleos essenciais, sobre Pseudomonas aeruginosa

\begin{tabular}{|l|c|c|}
\hline \multicolumn{1}{|c|}{ Tratamentos } & \multicolumn{2}{c|}{$\begin{array}{c}\text { Concentração de Óleos } \\
\text { Essenciais (\%) }\end{array}$} \\
\hline Nome científico & CIM & CBM \\
\hline Cymbopongon nardus & 6,25 & 6,25 \\
\hline Eucaliptus globolus & 12,50 & 25,00 \\
\hline Prunus amygdalus & 50,00 & 50,00 \\
\hline Rosmarinus officinalis & 25,00 & 25,00 \\
\hline Cinnamomum zeylanicum & 25,00 & 25,00 \\
\hline Cymbopogon citratus & 50,00 & 50,00 \\
\hline Citrus limon & 50,00 & 50,00 \\
\hline Caryophyllus aromaticus & 100,00 & 100,00 \\
\hline
\end{tabular}

Fonte: Dados da pesquisa

Os óleos essenciais apresentaram ineficácia frente a $P$. aeruginosa quando foram empregados em baixas concentrações $(3,13 \%, 1,57 \%, 0,78 \%, 0,39 \%, 0,20 \%, 0,10 \%$, $0,05 \%$ e $0,025 \%$ ), provavelmente, a excessiva diluição interferiu na atividade biocida.

Os mecanismos de ação dos compostos naturais sobre as bactérias estão relacionados à desintegração da membrana citoplasmática, desestabilização da força motora do próton (PMF), fluxo de elétrons, transporte ativo e coagulação do conteúdo celular. Nem todos os mecanismos de ação incidem em alvos específicos, e alguns sítios podem ser afetados em função de outros mecanismos ainda não determinados. Os óleos essenciais são conhecidos por terem um forte potencial antibacteriano e essa atividade biológica e, principalmente em função da sua composição, incluindo compostos aromáticos e terpênicos (LANGEVELD; VELDHUIZEN; BURT, 2014; SAVIUC et al., 2016).

Os desenvolvimentos realizados no campo científico, 
referentes às propriedades medicinais das plantas têm recebido grande interesse devido à baixa toxicidade, atividades farmacológicas e viabilidade econômica. Tais estudos se concentraram nos benefícios dos fitoquímicos extraídos de plantas e seus efeitos na saúde humana (AUDDY et al., 2003). De acordo com Djenane et al. (2012), os Serviços de Saúde Pública reconheceram óleos essenciais como substâncias seguras e que óleos essenciais contêm compostos que podem ser usados como aditivos antibacterianos.

Sienkiewicz et al. (2014) sugeriram que alguns óleos essenciais poderiam ser empregados na luta contra infecções causadas por bactérias multirresistentes e também como componentes de formulações para a higiene e desinfecção de ambientes. No entanto, Yap et al. (2014) afirmaram que os óleos devem ser utilizados em formas diluídas, especialmente quando aplicados diretamente a pele, sendo tão eficazes quanto os agentes antibacterianos químicos. Além disso, é importante que os micro-organismos não adquiram resistência aos óleos essenciais ou aos seus componentes.

Stefanakis et al. (2013) propuseram que, em função da eficácia dos óleos essenciais contra patógenos e contaminantes de alimentos, sejam desenvolvidas técnicas que permitam a sua aplicação na indústria de produtos alimentícios. Contudo, se os óleos essenciais forem utilizados para fins de preservação de alimentos ou fins medicinais, as questões de segurança e toxicidade terão de ser abordadas (YAP et al., 2014).

\section{Conclusão}

Verificou-se que todos os óleos essenciais apresentaram atividade antibacteriana, no entanto, os óleos de E. gobulus e $R$. officinalis foram mais eficientes frente a $E$. coli $(\mathrm{CBM}=3,13 \%)$, e menos eficazes frente a P.aeruginosa $(\mathrm{CBM}=25 \%)$, enquanto que o óleo de $C$. nardus apresentou atividade biológica frente a $P$. aeruginosa na concentração de $6,25 \%$. A atividade antibacteriana dos óleos essenciais avaliados aponta a possibilidade de desenvolver agentes antimicrobianos eficientes e de baixo custo no controle de $E$. coli e de $P$. aeruginosa.

\section{Referências}

ADUKWU, E. C. et al. Antimicrobial activity, cytotoxicity and chemical analysis of lemongrass essential oil (Cymbopogon flexuosus) and pure citral. Appl. Microbiol. Biotechnol. v. 100, n.22, p.9619-9627, 2016. doi: 10.1007/s00253-016-7807-y.

ANDRADE, M.A. Óleos essenciais de Cymbopogon nardus, Cinnamomum zeylanicume, Zingiber officinale: composição, atividades antioxidante e antibacteriana, Rev. Ciênc. Agron, v.43, n.2, p.399-408, 2012.

AUDDY, B. et al. Screening of antioxidant activity of three Indian medicinal plants, traditionally used for the management of neuro-degenerative diseases. J. Ethnopharmacol., v.84, p.131338, 2003. doi:10.1016/S0378-8741(02)00322-7

BATISTA, N.N. et al. Formação de biofilme por Pseudomonas aeruginosa sobre aço inoxidável em contato com leite e seu controle por óleos essenciais. Braz. J. Food Nut., v.25, n.1, p.1924, 2014.
BOUKHRAZ, A. et al. Evaluation of the bacteriostatic and bactericidal activity of essential oil of Thymus Satureioides. Int. J. Res. Stud. Sci. Eng. Technol., v.3, n.3, p.24-28, 2016.

CAMELO, A.L.M. et al. Análise comparativa da composição química volátil de amostras do alecrim in natura com a disponível comercialmente. Holos, v.5, p.191-198, 2014. doi: 10.15628/ holos.2014.2082

CLSI - Clinical and Laboratory Standards Institute. Publication M100-S23 Suggested Grouping of US-FDA Approved Antimicrobial Agents that Should be Considered for Routine Testing and Reporting on non fastidious organisms by Clinical L. 2013.

CHOUHAN, S.; SHARMA, K.; GULERIA, S. Antimicrobial activity of some essential oils-present status and future perspectives. Medicines, v.4, n.58, p.1-22, 2017. doi: 10.3390/ medicines 4030058

COSTA, A.L.P.; SILVA JUNIOR, A.C.S. Resistência bacteriana aos antibióticos e saúde pública: uma breve revisão de literatura. Est. Cientif., v.7, n.2, p.45-57, 2017. doi: 10.18468/ estcien.2017v7n2.p45-57

DE BILLERBECK, V.G. Huiles essentielles et bactéries résistantes aux antibiotiques. Phytothérapie, v.5, p.249-253, 2007.

DJELLOUL, R.; MOKRANI, K.; HACINI, N. Study of the antibacterial activity of the extract from the essential oil of eucalyptus globulus and Rosmarinus officinalis on Three Bacterial Strains. Int. J. Appl. Environ. Sci., v.12, n.1, p.47-56, 2017.

DJENANE, D. et al. Perspectives on the use of essential oils as antimicrobials against Campylobacter jejuni CECT 7572 in retail chicken meats packaged in micro aerobic atmosphere. J. Food Safety, v.32, p.37-47, 2012. doi: 10.1111/j.17454565.2011.00342.x

FARISA BANU, S. et al. Antivirulent properties of pnderexplored Cinnamomum tamala essential oil and its synergistic effects with DNase against Pseudomonas aeruginosa biofilms: an in vitro study. Frontiers Microbiol., v8, p.1144. doi: 10.3389/ fmicb.2017.01144

FAVRE, B. et al. Comparison of in vitro activities of antifungal drugs against a panel of 20 dermatophytes by using a microdilution assay. J. Clin. Microbiol., v.17, p.41-48, 2003.

FISHER, K.; PHILLIPS, C. Potential antimicrobial uses of essential oils in food: Is citrus the answer? Trends Food Sci. Technol., v.19, p.156-164, 2008. doi:10.1016/j.tifs.2007.11.006

FRACAROLLI, I.F.; OLIVEIRA, S. A.; MARZIALE, M. H. L. Colonização bacteriana e resistência antimicrobiana em trabalhadores de saúde: revisão integrativa Acta Paul Enferm., v,30, n.6, p.651-657, 2017. doi: 10.1590/1982-0194201700086

FURTADO, J.M. et al. Atividade antimicrobiana do extrato aquoso de Eucalyptus globulus, Justicia pectoralis e Cymbopogon citratus Frente a bactérias de Interesse. UNOPAR Cientif.: Ciênc. Biológ. Saúde, v.17, n.4, p.233-237, 2015.

GUIMARÃES, C.C. et al. Atividade antimicrobiana in vitro do extrato aquoso e do óleo essencial do alecrim (Rosmarinus officinalis L.) e do cravo-da-índia (Caryophyllus aromaticus L.) frente a cepas de Staphylococcus aureus e Escherichia coli. Rev. Bras. Biociênc., v.15, n.2, p.83-89, 2017.

LANGEVELD, W.T.; VELDHUIZEN, E.J.; BURT, S.A. Synergy between essential oil components and antibiotics: a review. Critic. Rev. Microbiol., v.40, n.1, p.76-94, 2014.

LIMA, C. V, R. et al. Ação antibacteriana do oléo essencial 
das folhas de Eucalyptus globulus, frente a patógenos multirresistentes, Diversitas J., v,4, n.1, p.242-252, 2019. doi: 10.17648/diversitas-journal-v4i1.633

LOUREIRO, R. J. et al. O uso de antibióticos e as resistências bacterianas: breves notas sobre a sua evolução. Rev. Port. Sau. Pub., v.34, n.1, p.77-84, 2016 doi:10.1016/j.rpsp.2015.11.003

MAN, A. et al. Antimicrobial activity of six essential oils against a group of human pathogens: a comparative study. Pathogens, v.8, n.15, p1-11, 2019 doi: 10.3390/pathogens8010015

MO, T.; ADEBAYO OS, A. Plant essential oil: an alternative to emerging multidrug resistant pathogens. J. Microbiol. Exp., v.5, p.1-10, 2017. doi: 10.15406/jmen.2017.05.00163

SAVIUC, C. et al. Rosmarinus officinalis essential oil and eucalyptol act as efflux pumps inhibitors and increase ciprofloxacin efficiency against Pseudomonas aeruginosa and Acinetobacter baumannii MDR Strains. Romanian Biotechnol. Lett., v.21, n.4, p.11782-11790, 2016.

SIENKIEWICZ, M. et al. The biological activities of Cinnamon, Geranium and Lavender essential oils. Molecules, v.19, n.12, p.20929-20940; 2014. doi:10.3390/molecules191220929.

SILVA, N.C.C.; FERNANDES JÚNIOR, A. Biological properties of medicinal plants: a review of their antimicrobial activity. $J$. Ven. Anim. Tox., v.16, n.3, p.402-413, 2010. doi:10.1590/S167891992010000300006.

SOLIMAN, S.S.M. et al. Essential Oils Synergize with Lawsone against Multidrug Resistant Pathogens. Molecules, v.22, p.22122223, 2017. doi: 10.3390/molecules 22122223

STEFANAKIS, M.K. et al. Antibacterial activity of essential oils from plants of the genus Origanum. Food Cont., v.34, p.539-546, 2013. doi:10.1016/j.foodcont.2013.05.024

SYLVESTER, P.W. Optimization of the tetrazolium dye (MTT) colorimetric assay for cellular growth and viability. Met. Mol. Biol., v.716, p.157-168, 2011. doi: 10.1007/978-1-61779-0126_9

TOMAZ, M. A. et al. Composição química e atividade alelopática do óleo essencial de eucalipto. Biosci. J., v.30, p.475-483, 2014.

TORTORA, G.J.; FUNKE, B.R.; CASE, C.L. Microbiologia. São Paulo: Artmed, 2012.

YAP, P.S.X. et al. Essential oils, a new horizon in combating bacterial antibiotic resistance. Open Microbiol. J., v.8, p.6-14, 2014. doi: $10.217 / 1874285801408010006$ 